\title{
Entre lógica e dialética: experiências de uma proposta em construção
}

\author{
Matheus Penafiel'
}

\begin{abstract}
Resumo
Este trabalho apresenta relatos de duas experiências didáticas realizadas pelo autor, ambas embasadas em uma proposta didática para o ensino de lógica e argumentação ainda em desenvolvimento. As experiências possibilitam suscitar algumas questões sobre a realização delas mesmas, a saber, se as atividades realizadas para atingir os objetivos da aprendizagem têm sido as melhores. Com a leitura se perceberá que não, e analiso os eventos na busca de um por quê. Após encontrar uma possibilidade de resposta, pretendo oferecer uma via alternativa que permita aprimorar as aprendizagens dos alunos.
\end{abstract}

Palavras-chave: experiência didática; diálogos platônicos; jogos dialéticos.

\section{Entre lógica y dialéctica: experiencias de una propuesta en desarrollo}

\begin{abstract}
Resumen
Este trabajo presenta informes de dos experiencias didácticas realizadas por el autor, sobre la base de una propuesta didáctica para la enseñanza de lógica y argumentación aún en desarrollo. Las experiencias permiten plantear algunas preguntas acerca de la realización de los mismos, a saber, si las actividades llevadas a cabo para lograr los objetivos del aprendizaje han sido los mejores. Después de leerlo, usted descubrirá que no es así, y analizo los eventos en busca de un por qué. Después de encontrar la posibilidad de respuesta, quiero ofrecer un medio alternativo de realizar las aprendizaje de los estudiantes.
\end{abstract}

Palabras clave: experimento didáctico; diálogos platónicos; juegos dialécticos.

1 Matheus Penafiel/Graduando/UFRGS/bolsista do PIBID Interdisciplinar UFRGS do Campus do Vale, penafiel.matheus@gmail.com 


\section{Introdução}

Apesar de os alunos do ensino médio (EM) reconhecerem no isolamento do pensamento individual uma necessidade para a filosofia, é recorrente em suas representações a ideia de que a filosofia se faz em debates. Tendo como pressuposto do projeto de pesquisa que embasa as experiências aqui relatadas que as aulas de Filosofia devem se desenvolver a partir das representações dos alunos, é prudente compreender o que está por trás de "debates".

Chamo a atenção para isso porque podemos dividir os discursos filosóficos, de forma geral, em dois: oral e escrito. Apesar de a forma de expressão do discurso filosófico atual ser quase que totalmente a escrita, deve-se reconhecer no princípio da história da filosofia a popularidade dos diálogos, mais especificamente dos diálogos socráticos. Os estudantes do nível médio, seja por ignorância, seja por desejo, parecem querer resgatar essa tradição oral da filosofia. No entanto, deve-se pontuar precisamente o que esperam dessa oralidade e como são frequentemente travados seus debates, pois se configuram como um dos desafios do professor de filosofia.

Os alunos do EM apresentam uma vontade muito forte de expor suas posições, mas o mesmo não pode ser dito sobre ouvir aquilo que outras pessoas têm a dizer sobre o mesmo assunto quando discordam. Esse cenário, sumariamente descrito, muitas vezes se encerra no jargão segundo o qual "cada um tem sua verdade". Este jargão é a encarnação do relativismo, problema que aparece sob várias formas e que, em todas elas, nos coloca o desafio de lidar com ele.

Observando esse cenário com o qual nos deparamos com certa frequência, desenvolvi uma proposta didática que embasou essas experiências. Tais experiências servem como retroalimentação para, junto das pesquisas teóricas, reelaborá-la, e são elas que relato nas linhas seguintes.

A proposta inicial era uma estratégia de ensino de tópicos de Lógica e Teoria da argumentação através de diálogos com e entre os alunos. A primeira etapa desta proposta se desenvolve com a problematização de um tema que Ihes seja caro, não necessariamente o que eles reconhecem como polêmicos, tal como a natureza do amor e da amizade, suas possíveis relações, para, em uma segunda 
etapa, eles debaterem sobre o tema em pequenos grupos. Nessa etapa, os alunos gravam suas conversas e depois degravam (transcrevem) o diálogo. A ideia é, posteriormente, analisar esses textos junto dos alunos na busca de padrões ou regras de argumentação, com o intuito de problematizá-las. O principal suporte teórico para essa etapa é o recente trabalho de Castelnérac \& Marion (2009) sobre os jogos dialéticos na Academia de Platão, no qual são explicitadas e exemplificadas as regras desses jogos. As regras são as seguintes:

- "(i) Os jogos envolvem sempre dois jogadores: um proponente $\mathbf{P}$ e um oponente O." (2009, p. 54);

- "(ii) Um jogo começa com $\mathbf{O}$ extraindo de $\mathbf{P}$ seu compromisso com uma afirmação ou tese A." (2009, p. 54);

- "(iii) O jogo então passa por uma série de perguntas e respostas que se alternam. O faz perguntas tais que P pode dar uma 'resposta curta': idealmente, mas não necessariamente, 'sim' ou 'não'." (2009, p. 56);

- "(iv) Procedendo assim, $\mathbf{O}$ extrai novos compromissos de P, por exemplo, o compromisso com afirmações $B$; $C$; etc., o que pode ser concebida como adicionado ao 'inventário de compromisso' ou 'painel de avaliação' de P." (2009, p. 56);

- "(v) P tem o direito de esclarecer ou ajustar uma concessão anterior, sempre que O distorce esta concessão em uma direção indesejável." (2009, p. 59);

- "(vi) $\mathbf{P}$ pode protestar contra as perguntas de $\mathbf{O}$ por formulando objeções." (2009, p. 59);

- "(vii) Se as perguntas de $\mathbf{O}$ são admissíveis à luz de (vi), então P deve dar uma resposta." (2009, p. 60);

- "(viii) O não pode introduzir qualquer tese $A$ sem que antes $\mathbf{P}$ tenha aceito A." (2009, p. 60);

- "(iv) Tento extraído de $\mathbf{P}$ o comprometimento com as teses, digamos, $B$

e C, O pode propor que eles raciocinem sobre a consistência do conjunto formado por A, B e C." (2009, p. 60); 
- " (x) Quando 0 conduziu P em um elenchus (contradição), a prática acaba com a vitória de O; P ganha evitando se contradizer." (2009, p. 62);

- "(xi) Há um limite de tempo para que o jogo se desenvolva" (2009, p. 68);

- "(xii) Estratégias de prolongamento são proibidas." (2009, p.68);

- "(xiii) Falácias são estritamente proibidas" (2009, p. 70);

- "(xiv) Uma vez que $\mathbf{P}$ tenha se comprometido com $A$ e que $A$ implica $B$, O pode forçar P a defender seu comprometimento com B." (2009, p. 74); - "(xv) Se $\mathbf{O}$ concedeu à $\mathbf{P}$ muitas sentenças, mas se recusa a se comprometer com a generalização, então $\mathbf{P}$ pode forçar $\mathbf{O}$ proporcionar um contra-argumento." (2009, p. 74).

Assim, a etapa seguinte se desenvolve com a leitura de um trecho de diálogo platônico que contemple o tema discutido por eles, analisando quais das regras discriminadas anteriormente estão ali presentes (se é que estão), verificando as similaridades $e$ as diferenças entre os diálogos transcritos pelos alunos, verificando a necessidade ou não de outras regras. Embora a etapa final pensada primeiramente fosse a de repetir a experiência de diálogo com os alunos para exercitar o método socrático, após as experiências que serão relatadas, pensei que esse exercício pode ser feito de mais de uma maneira, como espero que fique claro após os relatos.

Apesar de os diálogos serem necessários para o desenvolvimento dessa proposta tal como ela foi concebida previamente, na prática eles ocuparam um papel secundário, senão subserviente à Lógica em minha primeira experiência. Assim, contrariando o que seriam minhas intuições primárias e meus próprios objetivos, abri mão de um material riquíssimo para ir além no que diz respeito a Teoria da argumentação², pois os contextos em que nos enreda Platão através de suas obras não pode ser compreendido ou analisado tão somente com o aparato da Lógica. Portanto, o segundo relato serve não só para reelaborar a própria

\footnotetext{
${ }^{2}$ Apesar de não fazer referência a alguma bibliografia especializada no assunto, a sugestão de como ler os diálogos platônicos feita por Scolnicov (2003) suscita algumas questões pertinentes ao tema.
} 
proposta a fim de aperfeiçoá-la, mas também para se fazer justiça a complexidade literária dos diálogos platônicos.

\section{Primeiro relato: Ernesto Dorneles}

Na Escola Técnica Estadual Senador Ernesto Dornelles, onde eu atuava como bolsista de iniciação à docência do subprojeto do Pibid Filosofia, no primeiro período das manhã de terça-feira, o professor supervisor da turma me perguntou se não poderia ministrar algumas aulas de lógica. Apesar de ter aceitado a proposta do professor, só concebi a proposta sobre a qual escrevo após a palestra da professora Gisele Secco, intitulada "Diálogos que nossos alunos podem ler", em que tive o primeiro contato com as ideias de Castelnérac e Marion.

Como pensamos na problematização de um tema que, por um lado, engajasse os alunos na reflexão e, por outro lado, gerasse certo desconforto conceitual, a professora Gisele me aconselhou a usar um trecho de Grande Sertão: Veredas, em que Riobaldo, personagem principal do romance ornado por Guimarães Rosa, relembra alguns dos dias que passou ao lado de Reinaldo - dias diferentes do resto de sua vida, conforme afirma. O trecho é complexo, pois, além da linguagem algo regionalista e de complexa estruturação usada pela personagem narradora, seus sentimentos por esse amigo parecem oscilar entre a amizade e o amor, e o leitor se coloca em suspensão com relação à determinação do sentimento em jogo o trecho. O professor pode fazer emergir esse conflito de sentimentos nos termos de uma análise conceitual, embora não exclusivamente. ${ }^{3}$

Como essa etapa de problematização pressupõe a participação coletiva dos estudantes, e estando atento à pouca participação desempenhada por eles nas aulas do semestre anterior, bem como ao fato de que eram menos de vinte os alunos que se faziam presentes, recorri aos estudos apresentados em Além dos muros da escola, em que os autores apresentam, dentre as diversas possibilidades de configuração da sala de aula, o formato de $U$ ou $V$, mais adequada para a

3 Não se pode ignorar a dimensão literária do texto de Rosa, e por isso poder-se-ia propor um trabalho em conjunto com o professor de literatura para que a análise conceitual não sobreponha completamente à análise estética. 
atividade proposta (JOLIBERT; JACOB, 2006, p. 24-25). A sala foi organizada minutos antes da chegada dos alunos, e causou neles um esperado estranhamento.

Entreguei a eles o material com o trecho selecionado e pedi que fizessem uma leitura silenciosa, salientando a necessidade de anotar as palavras que não conheciam. Após, fiz uma leitura "corrida" do início ao fim do trecho, o que tenho repensado como prática. Quero dizer, após ter observado algumas aulas em meu estágio de docência, em que o professor faz uma leitura pausada e explicativa do texto que leem, penso que a minha não tenha sido a melhor estratégia. Um texto da complexidade do Grande Sertão: Veredas exige uma leitura calma e pontuada, o que eu, inadvertidamente, evitei.

Embora reconheça esse equívoco, o desenvolvimento da aula não foi prejudicado por esse motivo. Ao revés, atestando contrariamente à constante reclamação que se ouve desde os corredores da escola até os seminários de ensino, os alunos compreenderam aquilo que estava sendo descrito pelo texto. Enquanto eu escrevia no quadro o tema tratado pelo autor na narrativa, após Ihes ter perguntado qual seria e terem me respondido que era a amizade, iniciou-se um burburinho desconfiado e descontraído relativos à veracidade dessa constatação, pois não era exatamente "amizade" como classificariam alguns. Comprovavam que haviam compreendido a ambiguidade do sentimento descrito. Tentei, então, através de perguntas, extrair alguma leitura particular do que haviam compreendido, sem sucesso. Fosse por timidez, fosse por desinteresse, a discussão não desatava, até o momento em que um dos alunos, aparentemente incomodado com a narrativa, irrompeu a falar que aquilo era uma relação gay, e que, portanto, não se tratava de amizade. Recebi tal constatação com choque e tentei aparentar calma, ainda que, por segundos, não soubesse como lidar com a fala. Alguns alunos, em tom mais baixo e mais brando, ironizaram-no evocando falas dos então recentes debates políticos. Para não deixar que a fala do aluno ficasse sem resposta, questionei especificamente a ele se achava que não havia amor entre amigos. A resposta foi uma negativa categórica. Olhei para os demais alunos que pareciam, não com a mesma convicção, concordar com o colega. Escrevi no quadro, então, o que compreendi que fosse a opinião geral, de que não 
há amor na amizade. Disposta a frase no quadro, algumas alunas se manifestaram dizendo que não concordavam com o que estava escrito. Para não cometer o equívoco de falar por elas, perguntei se achavam que havia amor na amizade, o que responderam positivamente. Procurei alguma mudança de posição da parte dos rapazes, mas mantiveram suas posições, ainda que alguns parecessem incertos, então escrevi essa segunda opinião sem apagar a primeira.

Continuei questionando sobre aquilo que julgavam ser a amizade fingindo a busca por um conceito universal e colhendo opiniões diversas. Ao final da aula, criamos uma espécie de tabela sobre as amizades existentes, conforme suas divergentes representações, que as traduziram em: "Amizade sem amor", "amizade com amor", "coleguismo", "amizade falsa" e "amizade colorida". Acho prudente enfatizar que a "amizade colorida" partiu da pergunta de um dos alunos que me questionou onde ficaria entre as demais formas de amizade, questão que retornei aos demais estudantes a fim de que eles que a classificassem. Ficou em um misto de amizade com e sem amor, não sendo, necessariamente, nem uma, nem outra. Ficaram divididos até mesmo em classificar como uma forma de amizade.

Na semana seguinte, a disposição da sala foi alterada novamente. Dessa vez, as classes foram arranjadas três a três, condicionando os alunos a sentarem em trios. Novamente entraram com estranhamento. Entreguei o material didático preparado para aquela aula - um pequeno mapa conceitual que reproduzia aquilo que fora discutido na aula anterior, uma tirinha da personagem Armandinho e algumas perguntas que pretendiam guiar as discussões - e pedi que discutissem entre si aquilo que discutimos na semana anterior, gravando a conversa em seus celulares. Instruí que as perguntas disponíveis eram apenas guias para eles, mas que, caso as discordâncias fossem muitas enquanto tentassem responder a apenas uma delas, não seria necessário responder às demais.

Após breve momento de timidez, conforme foram fluindo as discussões, os alunos foram dialogando com bastante desenvoltura. Reservei a aula seguinte para que degravassem as conversas. Enquanto caminhava pela sala, ouvi um dos alunos dizendo que seria melhor não transcrever um dos termos utilizado durante a conversa, e eu respondi que podiam transcrever conforme disseram, que se fosse 
necessário, eu advertiria. Faço esta observação para refletir sobre ela nas considerações finais.

Alguns dos alunos não conseguiram terminar a transcrição até o término do período, e sugeri que entregassem ao professor supervisor na manhã seguinte que eu buscaria à tarde. Como combinado, fui buscar os diálogos degravados, mas nenhum aluno havia entregue.

Dos diálogos entregues, nenhum satisfazia aquilo que eu tinha em mente. Em primeiro lugar porque nenhum apresentava discordância entre as partes dialogantes. Em segundo lugar porque alguns deles não eram nem diálogos, mas uma tentativa de resposta às perguntas listadas no material em que os alunos alternaram quem respondia.

Para a aula seguinte, preparei um material didático com um trecho de Lísis, de Platão4. Penso hoje que a escolha do trecho não foi a melhor, pois priorizei um em que fossem mais explícitas as regras elencadas por Castelnérac e Marion em detrimento, talvez, de um que abordasse questões ainda pertinentes às representações dos alunos sobre a amizade e o amor. Ou ainda poderia ter usado dois trechos, um para situá-los no enredo e nos conflitos conceituais sobre os quais começam a discutir as personagens, e depois explorar o outro a fim de explicitar as regras.

A leitura do diálogo transcorreu com a mesma apatia anterior às primeiras aulas. Neste sentido, concluí que foi um erro voltar à disposição normal das classes, pois, como pretendia continuar fazendo uma reflexão coletiva sobre a amizade nesse momento com o diálogo platônico, fazia sentido ainda dispor elas em $\mathrm{V}$.

Devido a alguns problemas institucionais, a turma ficou sem algumas de suas aulas na terça-feira, fazendo com que minha agenda de planejamento se reduzisse a apenas mais uma aula. Arrisquei, então, fazer a leitura de um trecho menor de Lísis, um tanto mais atrativo, à luz do quadrado das oposições entre proposições categóricas, tentando extrair com eles o conceito de inconsistência e mostrando,

${ }^{4}$ O artigo de Cornelli (2010) oferece importantes observações referentes à leitura dos diálogos platônicos em sala de aula, e o já mencionado artigo de Scolnicov pode complementar essas observações. 
através do quadrado, quais as possibilidades de analisar um sistema de crenças inconsistente. Como esta foi a última aula, não pude concluir se as aulas foram proveitosas e se houve progresso no desenvolvimento de seus conceitos, nem se compreenderam do que se tratava do método socrático ou, ao menos, de algo aparentado.

\section{Segundo relato: Pré-Vestibular Esperança Popular}

No cursinho Pré-Vestibular Esperança Popular, onde sou o responsável pela disciplina de Filosofia e disponho de um período a cada duas semanas, a abordagem foi, apesar de norteada pela mesma proposta, um tanto distinta, pois o objetivo era outro. Se, por um lado, na escola Ernesto Dornelles priorizei uma agenda para desenvolver tópicos de Lógica, no Esperança resolvi enfatizar, fazendo as devidas observações dramáticas dos diálogos platônicos, o movimento de distinção do discurso filosófico desempenhado por Platão frente aos demais discursos populares em Atenas, os poéticos e os sofísticos. Não abri mão, no entanto, de começar com o mesmo trecho de Grande Sertão: Veredas.

Ao contrário do que ocorreu na Ernesto Dornelles, os alunos do Esperança, apesar de reconhecer o conflito existente no sentimento manifesto de Riobaldo, não conseguiam traçar distinções relevantes entre o amor e a amizade. Embora eu quisesse traçar um curso de discordância semelhante ao que ocorreu na experiência anterior, e conforme não fui obtendo sucesso, inverti a estratégia: passei a questionar aos alunos se as características atribuídas a um dos conceitos não poderiam ser atribuídas ao outro também. Usei de exemplos para demarcar as semelhanças, e encerramos a aula sem uma distinção relevante sequer. Isso, apesar do que pode parecer, deve ser felicitado: a ideia não era que os alunos saíssem com a impressão de que a tarefa dos filósofos é coisa que se faz em 50 minutos, mas que é necessário um segundo olhar, mais cauteloso, sobre os conceitos que usamos cotidianamente. Em termos nietzschianos, podemos dizer que trata-se de "habituar o olho à calma, à paciência (...); adiar o juízo, aprender a envolver e cercar o caso particular por todos os lados" (NIETZSCHE, 2013, p. 72). 
Ainda estava incerto quanto ao modo de conduzir a segunda etapa do planejamento quando uma das atividades de formação extraclasse ao estudantes, cuja participação do corpo docente era imprescindível, foi cancelada de última hora, e improvisadamente sugeri a tarefa. Solicitei aos alunos que se reunissem em pequenos grupos para que, retomando o tema tratado na aula anterior, o debatessem e gravassem o debate, salientando que deveriam degrava-lo depois. Enunciar isso logo foi um equívoco, que será devidamente observado posteriormente.

Passados alguns minutos, circulei pela ampla sala que comportava os quarenta alunos. Uma das alunas me questionou se seria necessário escrever, de fato, em formato de fala, especificando quem fala, o que respondi positivamente. Percebi não só que essa era a dúvida de mais alguns, como também que outros não haviam compreendido que era para dialogar, pois elencavam os vários tipos de amor que conheciam e tentavam prestar as devidas definições. Reiterei a necessidade de que fosse dialogado, gravado e transcrito o diálogo para que me entregassem na semana seguinte os textos, pois basearia minhas aulas neles. Uma aluna questionou se poderia ser feito o diálogo por WhatSapp, e aceitei a proposta. Alguns outros alunos começaram a escrever enquanto falavam, o que, em princípio, não vi problema. Após receber os textos na semana seguinte, no entanto, percebi que não retrataram com fidelidade a espontaneidade das conversas. Um grupo específico formado por cinco garotas - o que permiti para chamar a atenção posteriormente para a dificuldade de se manter um fio condutor em um grupo tão grande - conversavam com muito entusiasmo e enfatizavam em tom elevado suas discordâncias. Nada disso foi retratado de forma escrita, porém.

Para a aula seguinte, ocorrida após duas semanas, pretendia incorporar algumas passagens do que me fosse entregue pelos alunos para utilizá-lo para comparar com trecho de algum diálogo platônico. Então, como apenas quatro me entregaram a atividade, dois em formato de diálogo, nenhum que apresentasse discordância, resolvi suspender o uso dessa metodologia. Também o fiz a fim de dar vazão a uma questão alertada por Jeanne-Marie Gagnebin (2006, p. 205), a saber, que a filosofia, incorporada nos diálogos de Platão, visava a se 
distinguir de dois dos principais discursos usados em Atenas: a poesia épica e trágica e a retórica e a sofística. Quero deixar claro, desde já, o que adiante detalharei, que ainda para esses fins eu poderia ter incorporado os textos dos alunos no material didático.

Por esses motivos, usei de um trecho de A República em que Sócrates discute com Polemarco sobre o que é a justiça. Em caixa de texto no material didático, frisei as características históricas do interlocutor de Sócrates, a saber, que no governo dos Trinta Tiranos, foi preso e obrigado a beber cicuta (2005, p. 1, n.), mesmo fim de Sócrates, deixando em suspenso a intenção de Platão com a composição dramática. Ainda sobre o material didático: como não escrevi os nomes daqueles que falavam, deixando a interpretação ser feita a partir da narrativa de Sócrates, os alunos sentiram dificuldade de identificar que personagem falava o quê. Creio que, para fins didáticos, manter a formatação original nem sempre é a melhor escolha.

Com os alunos, reconstituí as afirmações com as quais se compromete Polemarco no desenvolvimento do diálogo. Conseguiram acompanhar com certa facilidade até o momento em que o interlocutor de Sócrates entra em contradição. Embora regulassem a surpresa, não conseguiam conter o tom de espanto no olhar, como o de alguém que não entende o que acaba de acontecer. Perguntei se haviam dúvidas, e responderam com risadas debochadas. Como chegamos ao final da aula e era o último período da noite, sugeri que continuássemos na aula seguinte.

Após as duas semanas que intervalam uma aula e outra, trabalhamos com alguns trechos de diversos diálogos platônicos com o objetivo de exemplificar a afirmação de Gagnebin. Os primeiros diziam respeito às críticas aos sofistas: um de A República, em que Platão arranja a trama para criticar o tratamento por parte dos sofistas do conhecimento como mercadoria; outro de Górgias, em que Sócrates critica os "discursos prolixos" de Polo e, em seguida, convida Górgias para um "jogo" de perguntas e respostas. O terceiro trecho era uma fala de Sócrates a respeito dos elogios a Eros proferidos em Banquete. 
Então, demarcado de forma negativa os discursos não usados pelos filósofos, e como faltasse tempo para voltar ao trecho da República abordado na aula anterior, convidei os alunos a participar comigo do mesmo jogo de perguntas e respostas para que o vivenciassem. Para facilitar a tarefa, usei um exemplo da geometria. Desenhei no quadro um quadrado (ou antes, uma figura aproximada) e Ihes perguntei que figura era. Alguns me responderam que se tratava de um quadrado. Perguntei aos demais se concordavam, e responderam que sim. Perguntei como poderíamos definir o quadrado, e alguns responderam que "tem quatro lados iguais". Perguntei aos demais se concordavam, e foram unânimes: é uma figura de quatro lados iguais. Escrevi a definição no quadro, logo abaixo da figura. Em seguida, disse algo sobre os conceitos, o que deveria ter sido melhor explorado em aulas: as definições têm a propriedade de serem trocados com as palavras a que referem sem perda de sentido. Assim, para após projetar essas questões nas condições do quadrado das oposições, escrevi que "Todo quadrado é uma figura de quatro lados iguais" e, logo abaixo, "Toda figura de quatro lados iguais é um quadrado". Aceito isso pelos alunos, desenhei um losango ao lado do quadrado e um sinal de igual entre eles. Questionei se o losango era um quadrado, o que responderam negativamente. Perguntei, então, se sendo nossa definição de quadrado uma figura de quatro lados iguais e sendo o losango uma figura de quatro lados iguais, se acaso não deveria ser o losango ser considerado um quadrado. A turma ficou dividida. Alguns mantiveram a posição de que eram figuras diferentes, outros concordaram que, segundo nossa definição, forçosamente deveriam aceita-lo como quadrado. Começaram a discutir entre eles sobre quais seriam as diferenças entre ambas as figuras, e percebi que a imprecisão do desenho dificultou a compreensão, pois alguns acreditavam que a segunda figura que desenhei possuía ângulo de noventa graus. Intervi na discussão afirmando que não e tentei concertar o desenho. Visto que não fosse suficiente, disse que os ângulos opostos do losango são iguais entre si. Partindo da opinião de que se tratava de figuras distintas, portanto, questionei qual deveria ser nossa correção conceitual. Alguns responderam que deveríamos acrescer que todos seus ângulos são iguais, outros que seus ângulos são de noventa graus. Afirmei que ambas satisfaziam a definição. 
Depois de sanada a divergência conceitual, expliquei através do quadrado das oposições o que gerava o conflito. Que, se tínhamos como verdadeira a sentença "Toda figura de quatro lados iguais é um quadrado", não poderíamos assumir como verdadeira também a sentença "Alguma figura de quatro lados iguais/um losango não é um quadrado", pois existe uma relação de contradição entre elas. Expliquei o que é essa relação de contradição e também o que é a de contrariedade, e explicitei que o que faz Sócrates nos diálogos platônicos é evidenciar alguma dessas relações no conjunto de crenças suportado por seus interlocutores que, sem se dar conta, defende a verdade de duas sentenças que não podem ser verdadeiras ao mesmo tempo 5 .

Apesar de não ter realizado avaliação com os alunos para medir o quanto apreenderam, a maneira como respondiam às perguntas mostrou que compreenderam bem as relações. Deve-se ainda retornar aos conteúdos em momento propício, mesmo abordando outro momento histórico da filosofia, para atestar o aprendizado.

\section{Conclusão}

As regras identificadas pelos filósofos Castelnerác e Marion não foram trabalhadas em nenhuma das experiências, como deve ter ficado claro nos relatos. Essa é a etapa de maior frustração da sequência, pois foi objetivo primeiro do planejamento, mas nunca o de chegada das práticas. Uma das dificuldades encontradas na realização dessas sequências didáticas, e que, por falta de maestria, não soube solucionar em tempo, foi a ausência de discordância por parte dos estudantes. Isso se configura em uma dificuldade porque, como um dos objetivos que se pretende com a sequência é o de que os alunos percebam a existência e a importância de estratégias de argumentação partindo de uma oposição clara de opiniões entre eles e através da comparação entre seus diálogos e os diálogos platônicos; quando não há por parte dos estudantes essa

\footnotetext{
${ }^{5}$ Esta caracterização vale não somente para relações entre sentenças contraditórias, mas para as contrárias também. Isto é, sentenças que podem ser falsas ao mesmo tempo, mas não verdadeiras, verificadas pelas relações entre as universais afirmativas e as universais negativas.
} 
divergência, não é possível essa comparação. No entanto, após essas experiências, penso que todo tipo de discurso usado pelos estudantes pode ser incorporado no material didático, mesmo que sirva como um exemplo negativo. Por exemplo, um dos alunos do Esperança não me entregou um diálogo, nem uma definição do que compreendia como sendo o amor, mas sim o trecho do poema de Camões já desgastado na música da Legião Urbana, que diz que "Amor é fogo que arde sem se ver/ é ferida que dói e não se sente/ é contentamento descontente". Ora, poderia ter usado esse discurso para abordar o tema da crítica de Sócrates aos poetas, cujo discurso seria rebuscado, enigmático e sem comprometimento com a verdade. Dessa forma, ficaria mais claro aos estudantes que aquilo que Sócrates tenta combater nos diálogos platônicos não é outra coisa senão nossa prática discursiva corrente, em que, muitas vezes, recorremos à autoridade de poetas, de humoristas e do senso comum sem nos preocupar com o comprometimento deles para com a verdade. Por essa via negativa dos outros discursos, poderíamos voltar novamente nosso olhar para o discurso dialético, observando, então, quais suas diferenças em relação ao poético, ao sofístico, ao dos humoristas, ao do senso comum etc. Após essas reflexões, acho imprescindível oportunizar aos estudantes a possibilidade de que os discursos presentes em sua cultura e em seu cotidiano invadam tais práticas, para que sobre elas também possamos lançar um olhar cauteloso, que os cerque por todos os lados. Assim, poderíamos nos voltar para as regras dos jogos dialógicos enquanto análise de teoria da argumentação e, posteriormente, aos conceitos lógicos que o suportam, tais como os de inconsistência, contradição e contrariedade.

Sobre os diálogos retratados sem fidelidade na escrita, fiquei algum tempo pensando. Minha preocupação era a de que, tendo realizado o diálogo como eu queria, mesmo que exageradas as emoções em seu curso, já haviam concluída a primeira etapa, e bastava apenas transcreve-lo, o que não foi efetuado. Então, na tentativa de sanar esse problema, creio que a melhor hipótese é a de que se deva, antes, problematizar com os alunos também o que compreendam que seja um debate, mostrando exemplos em formato de vídeo, por exemplo. Isso para evocar a necessidade de uma divergência entre as opiniões dos debatedores e, a partir de 
suas respostas, dizer o que se espera ou o que não se espera que façam. Enquanto é feita a problematização do que é um debate, também que se faça a problematização do que seria a transcrição dele. Usando de exemplos, o professor poderia retificar qualquer equívoco que houvesse por parte de seus alunos.

O que me lembra da etapa final, não realizada em nenhuma das experiências por falta de tempo. A proposta inicial era de que, transcorrida todas as etapas anteriores, se realizasse um novo diálogo por parte dos alunos em grupos. Isso para que se verificasse o aprendizado. No entanto, penso que a atividade é insuficiente. Por isso, creio que uma melhor opção seria a de solicitar aos alunos que eles elaborassem uma narrativa dialógica tal como os diálogos platônicos: isso é, usando de referência as personalidades existentes, criar cenas em que eles ou outras personagens debatam com alguma personalidade cuja opinião Ihes seja contrária, fazendo, como faz Sócrates, com que ele entre em contradição, sempre atentado para a reconstituição de um cenário. Penso que uma atividade criativa assim seria mais fiel à verificação das aprendizagens e também que possibilitaria uma intervenção produtiva por parte da disciplina de Língua Portuguesa e/ou Literatura. Os conteúdos programáticos de cada uma das disciplinas, talvez, fariam mais sentido se não fossem ministrados dissociadamente, mas sim se fossem associados. A interseção de ambas as disciplinas possibilitaria uma abordagem mais rica dessa proposta didática.

\section{Referências bibliográficas}

CASTELNÉRAC, Benoît \& MARION, Mathieu. "Arguing for Inconsistency: Dialectical Games in the Academy". In PRIMIERO, Giuseppe (ed.), Acts of Knowledge: History, Philosophy and Logic. College Publications, 2009, pp. 45-84.

CORNELLI, Gabriele. "História da filosofia antiga: começar pelo diálogo". Em: CORNELLI, Gabriele et al. Filosofia: Ensino Médio. Brasília: Ministério da Educação, Secretaria de Educação Básica, 2010. [Coleção Explorando o Ensino, v. 14], pp. 4558.

GAGNEBIN, Jeanne Marie. Lembrar escrever esquecer. São Paulo, Editora 34, 2006.

JOLIBERT, Josette; JACOB, Jeannette (Org.). Além dos muros da escola. Tradução de Ana Maria Netto Machado. Porto Alegre, Penso, 2006. 
NIETZSCHE, Friedrich W. Crepúsculo dos ídolos. Tradução, apresentação e notas de Renato Zwick. Porto Alegre, L\&PM, 2013.

PLATÃO. A República. Introdução, tradução e notas de Maria Helena da Rocha Pereira, 9. ed. - Lisboa, Fundação Calouste Gulbenkian, 2005.

Lísis. Introdução versão e notas de Francisco de Oliveira. Brasília, UNB, 1995.

ROSA, João Guimarães. Grande sertão: veredas. 18. ed. - Rio de Janeiro, Nova Fronteira, 1985.

SCOLNICOV, Samuel. "Como ler um diálogo platônico". HYPNOS ano $8 / n^{\circ} 11-2^{\circ}$ sem. São Paulo, 2003, pp. 49-59. 